\title{
Principles of explanation in e-commerce system based on sales dynamics
}

Leshchynskyi Volodymyr $^{1}$

Leshchynska Irina ${ }^{2}$
${ }^{1}$ Kharkiv National University of Radio Electronics, 14 Nauky Ave, KharkivUA-61166,Ukraine,volodymyr.leshchynskyi@nure.ua

${ }^{2}$ Kharkiv National University of Radio Electronics, 14 Nauky Ave, KharkivUA-61166, Ukraine, iryna.leshchynska@nure.ua

\begin{abstract}
The problem of forming explanations to the recommendations of items in the electronic commerce system is considered. The principles of constructing explanations that take into account changes in demand for goods and services are proposed. The first principle involves the use of a quantitative indicator as an explanation for a recommended subject. The second principle is associated with an iterative refinement of this quantitative indicator when recording new information about the choice of users in the database of the ecommerce system. The third principle postulates the use of implicit feedback from the user to construct explanations. As this feedback, information on sales of items is used, since this information is confirmed by the payment of users. The developed principles make it possible to formulate an onlineexplanation for the recommendations received, taking into account current data on sales of goods or services.
\end{abstract}

Keywords: recommendations, explanations, recommender subsystems, personalization of sales, e-commerce.

\section{INTRODUCTION AND PROBLEM STATEMENT}

E-commerce systems have gained significant competitive advantage over traditional offline channels because they provide support for consumer choice through advisory subsystems [1]. Such support is realized by creating a personalized list of recommended objects, taking into account the interests of the particular consumer.

Recommendations use information about the selection of products and services by users with similar preferences. Similarity of preferences is established on the basis of comparison of the goods and services sold to these consumers. The use of recommendations greatly simplifies consumer choice, which has led to an increase in the popularity of ecommerce systems.

In order to increase user confidence in the proposed list of goods and services, the recommendation may be supplemented by an explanation [2]. Explanations allow the user to simplify their selection of products from the recommended list, reduce time spent buying goods and services, which in turn leads to increased sales in the e-commerce system.

Explanations increase customer loyalty in the case of inaccurate recommendations that do not fully meet consumer preferences. The reason for the inaccuracy of the recommendations is the irrelevance of the ranking of goods and services in the recommended list due to incomplete information about the interests of the consumer or about the characteristics of the goods.

The first case is characteristic of the cold start of the recommendation subsystem. The recommendation subsystem perceives the new user as "cold" because it has no information about the history of its choice and therefore cannot determine its preference for goods and services [3].
The second case usually occurs as a result of user shilling attacks. Such attacks are intended to increase sales of the target assets and reduce sales of competitors' products. To achieve this, information on product ratings is distorted through the use of fake user profiles [4]. Personalized recommendations after a shilling attack contain a list of objects that are fit for the purpose of the attack.

However, these recommendations do not take into account the interests of real buyers of goods and services. As a result, confidence in the e-commerce system is diminished, which may reduce demand for goods and services.

Existing approaches to explanatory formation are a further development of methods for explaining the results of logical inference in expert as well as precedent systems. These approaches are complemented by the criteria for evaluating explanations. Compliance with the above criteria makes it possible to increase sales of goods and services [5].

However, it should be noted that existing approaches to constructing explanations do not consider changes in consumer interests and characteristics of objects over time. A temporal model that integrates such changes integrally is proposed in [6], but the issues of using this model to form explanations need further consideration.

Thus, the problem of developing explanatory principles based on the dynamics of sales of goods and services needs further research.

\section{PROBLEM SOLUTION AND RESULTS}

The suggested explanatory principles in the e-commerce advisory subsystem take into account changes in user demand over time. In particular, the increase in demand for a particular product can be an explanation for users regarding the popularity and high consumer characteristics of the product compared to competitors' products.

This approach should consider the criteria for evaluating changes in user choice, changes in sales resulting from the use of explanations [6].

The proposed principles of explanatory construction include:

- a quantitative assessment of the explanation for each recommended item;

- iterative clarification of explanations in order to take into account changes in consumer preferences over time;

- the use of implicit user feedback.

The first principle corresponds to a set of criteria for evaluating changes in user choice. This principle makes it possible to abstract from the characteristics of a particular object, since such characteristics are taken into account by the recommendation algorithms in determining the liking of the preferences of different users.

According to this principle, the explanation should reflect the popularity of each product or service. The quantification gives an opportunity to compare the popularity of different 
items, as well as the changes in popularity over time. Therefore, quantitative assessment makes it possible to satisfy the criterion of confidence [2].

According to this principle, an explanation in numerical form $g_{j}$ of an item $i_{j}$ can be represented as a total change in the interests of users for that object over the selected period of time:

$$
g_{j}=\sum_{k: \Delta t_{k} \in T} \Delta_{k, j},
$$

where $\Delta_{k, j}$ - change of interest of users to the item $i_{j}$ in the interval of time $\Delta t_{k} ; T$ - the period of time for which explanations are formed.

The essence of the second principle is to iteratively implement the sequence of adjusting explanations as new consumer choice data is used. This sequence contains the following steps.

Step 1. Formation of explanations for received recommendations according to (1).

Step 2: Implement user feedback from explanations.

In this step, the information in the e-commerce system database changes after the user uses the explanations. Such information may include a list of user-viewed pages of an ecommerce site, change in ratings, increase or decrease in sales.

Step 3: Calculate refined explanations for feedback from the recommendation subsystem user.

The difference between this step and step (1) is to change the time period for the explanation $T$. That is, when clarifying explanations, a "sliding window" is used:

$$
T_{i+1}=T_{i}-\Delta t_{1}+\Delta t_{K+1},
$$

where $T_{i}, T_{i+1}$ are variants of the periods $T$ of time for which explanations on iterations $i, i+1$ are determined; $\Delta t_{1}$ the first time interval in the period $T_{i} ; \Delta t_{K+1}$ - the last time interval in the period $T_{i+1}$.

According to expression (2), at each iteration the time period for constructing explanations is shifted by an interval $\Delta t_{K+1}$ on a time scale.

For all time intervals, the following condition is true:

$$
(\forall k \forall m, k \neq m,)\left|\Delta t_{k}\right|=\left|\Delta t_{m}\right|,
$$

where $\Delta t_{k}, \Delta t_{m}$ are two arbitrary intervals within a time period $T$.

Steps 2 and 3 are repeated as new information is received from users.

The second principle makes it possible to satisfy the Scrutability criteria of the first group and the Persuasiveness criteria of the second group. The Scrutability criterion is aimed at assessing the change in user interests based on the explanations received. To determine such an estimate, it is necessary to compare the list of goods and services received by the user before and after clarification.

The implicit feedback principle eliminates the intentional influence of the user on the explanations received. When making recommendations, they usually use either explicit or implicit feedback.
Explicit feedback is realized through user-rated items. However, such ratings can be faked in the case of shilling attacks. Therefore, using explicit feedback can lead to incorrect explanations.

Implicit feedback comes from moving a user through the pages of an e-commerce site and through a sales log. The first variant of implicit feedback reflects the potential interests of the user. Registration of this information requires the use of appropriate e-commerce site software. It should also be noted that such information is not always reliable, as the buyer may consider alternative purchases, be interested in the characteristics of the goods and services, etc. On the other hand, the interest of the user in the purchase of goods and services is confirmed by his expenses. That is, the latest information is relevant to the interests of the user. This indicates the importance of using the implicit feedback principle. The feedback is represented by the number of sales of items for which an explanation is being formed.

According to this principle, the formation in the explanations (1) uses the difference in the number of sales of items directly for a certain time interval, or for a pair of intervals within one time period.

\section{CONCLUSIONS}

The principles of explanation are suggested taking into account changes in requirements and interests of users. The proposed principles include the use of quantitative explanation of a recommended product or service, an iterative refinement of the explanation as new user choice information emerges, and the use of implicit feedback to construct explanations. Implicit feedback is information about sales of goods and services within a defined period of time, broken down by intervals of the same length over time.

The proposed principles make it possible to form an explanation based on objective data about changes in sales of goods or services. The objectivity of this data is confirmed by the costs of consumers.

\section{REFERENCES}

[1] Aggarwal C. (2017). Recommender Systems: The Textbook, New York: Springer. 498 p.

[2] Tintarev N., Masthoff J. (2007). A survey of explanations in recommender systems, in IEEE 23rd International Conference on Data Engineering Workshop, 801-810.

[3] Chalyi S., Leshchynskyi V., Leshchynska I. (2019). Method of forming recommendations using temporal constraints in a situation of cyclic cold start of the recommender system. EUREKA: Physics and Engineering, 4, 34-40 DOI:10.21303/2461-4262.2019.00952.

[4] Chala O., Novikova L., Chernyshova L. (2019). Method for detecting shilling attacks in e-commerce systems using weighted temporal rules. EUREKA: Physics and Engineering. Vol. 5, 29-36. DOI: 10.21303/2461-4262.2019.00983

[5] Tintarev N., Masthoff J. (2012) Evaluating the effectiveness of explanations for recommender systems, User Model User-Adap Inter Vol 22, 399-439.

[6] Modelyuvannya poyasnen shodo rekomendovanogo pereliku ob'yektiv z urahuvannyam temporalnogo aspektu viboru koristuvacha / S. F. Chalyj, V. O. Leshinskij, I. O. Leshinska // Sistemi upravlinnya, navigaciyi ta zv'yazku. - 2019. - Vip. 6. - S. 97-101. - Rezhim dostupu: http://nbuv.gov.ua/UJRN/suntz_2019_6_19 